\title{
Recordando al prof. Manolo Rodríguez Alonso
}

\author{
JÚLIA BUTINYÀ \\ Universidad Nacional de Educación a Distancia \\ juliabutinya@gmail.com
}

Buen amigo de casi 30 años, espacio de tiempo en el que se puede dar por consolidada una amistad. Por ello, en su memoria, voy a recordar algunos trazos de esos decenios, que justifican que le hagamos estos escritos en homenaje.

Y el lugar más adecuado para hacerlo es en la revista que fundamos, no sólo existiendo en calidad de revista, sino incluso antes de serlo, pues empezó a tener vida recogiendo las primeras Jornadas de estudios comparatistas de las tres lenguas y literaturas (catalán, gallego y vasco), promovidas por distintas Universidades de Madrid. Aquí, pues, es donde debe constar el más cálido recuerdo hacia el profesor Rodríguez Alonso por parte de los colegas que trabajamos codo a codo para asentar dichos estudios en esta ciudad, que sabe absorber iniciativas y ayuda a llevarlas a cabo.

Las aventuras filológicas emprendidas a tal fin culminaron en el máster Literaturas hispánicas (catalana, gallega, vasca) en el contexto europeo, dentro del programa «Lenguas Europeas y sus Literaturas: Teorías y Aplicaciones» - aprobado por el Ministerio en 2007, considerándolo exclusivo en España y fuera de ella-. Compartimos tales vivencias, desde el principio y en la mejor armonía, con el profesor de vasco, Patricio Urkizu, llegando a formar lo que podríamos denominar un terceto académico, ya que la conjunción de las tres disciplinas filológicas era imprescindible. Un hito, posterior al máster, tuvo lugar en 2010 en el Día de la UNED, dedicado en «Reconocimiento a las lenguas de España», en que se invistieron como Doctores Honoris Causa en Filología a tres autoridades de estas culturas: Xesús Alonso Montero, Antoni $\mathrm{M}^{\mathrm{a}}$ Badia i Margarit y Jean Haritschelhar. Y a raíz del hecho de recordarlo, cabe añadir que, fortuitamente, don Xesús es tío carnal de nuestro buen amigo Manolo.

El ojo del huracán de las actividades que desplegamos en aquel tiempo - desde los años 80, pero subrayadas al contar con la colaboración de nuestro profesor en la misma UNED - se centraba en las Jornadas mencionadas. Por ello, la manera en que puede tener más utilidad la exposición de su ánimo y dinamismo es haciendo un recorrido por las mismas, ${ }^{1}$ pues son testimonio expresivo de dicho

1 Puede verse un resumen, realizado a sugerencia del Dr. Antoni Ma Badia i Margarit, en Butinyà (2003). 
enfoque comparatista. Enfoque que fue promovido y protagonizado desde las Universidades madrileñas, pero al que se adherían distintas instituciones, como la fundación Ortega y Gasset, y que se llevó a cabo con soporte no exclusivamente académico, ya que solían colaborar los gobiernos autonómicos de los distintos territorios de estas lenguas.

El primer volumen —editado en 1991 - recoge las actas de unas Jornadas que no hemos querido borrar de la memoria, aunque son en realidad prehistoria, por estar realizadas y publicadas - en colaboración con el profesor Ramón Sarmiento - en la Universidad Autónoma de Madrid, donde había aún asignatura. Participó Manuel Rodríguez Alonso con la conferencia - publicada en las pp. 63-71-Lengua y literatura gallegas desde 1975. El profesor da razón de esta periodización desde el comienzo del trabajo con un planteamiento entonces harto novedoso:

La muerte del general Franco y los cambios políticos que siguen van a suponer unas condiciones nuevas para las lenguas y cultura gallega, catalana y vasca. El gallego, gracias a esta transformación democrática, va a alcanzar un lugar en la enseñanza que nunca hasta ahora había tenido y también en los medios de comunicación social, puesto que desde 1985 existe una televisión gallega. A pesar de todos los pesares, el gallego como lengua ha alcanzado una valoración y respeto que muy pocos esperábamos en 1975 que hubiese logrado.

Siguen las actas de las Jornadas de 1991, que se publicaron en 1992 como II volumen de la «Revista de Lengua y Literatura catalana, gallega y vasca», que sale ya en la UNED, donde ha seguido editándose hasta hoy. Participa también Manuel Rodríguez Alonso con dos artículos, de literatura y de lengua: Los Juegos Florales en la literatura gallega (pp. 59-62) y La dialectología gallega (pp. 63-72). Las de 1993, realizadas conjuntamente con la Universidad Complutense, aparecen como volumen III en 1994, y en 1996 las correspondientes a 1994 y 1995; nuestro profesor asistió y colaboró en la organización de todas ellas.

El volumen V — de 1998 — aúna lo que ya son las IX Jornadas, aumentadas con un grueso bloque de artículos. A su vez, el profesor colabora en los IV Premios de Ensayo de catalán, gallego y vasco (UNED), que recayó en gallego en el trabajo de Henrique Monteagudo Romero: Martín Sarmiento e o idioma galego no contexto ideológico e histórico-lingüístico.

El volumen VI, editado en 1999, cuenta ya con un cuerpo de 10 artículos de lengua y literatura gallega y de 9 reseñas. Sigue estas proporciones, de acuerdo con el ritmo bianual de publicación, el VII, de 2000-2001, contando siempre con la presencia e iniciativas del Dr. Rodríguez Alonso, miembro además del comité de redacción de la revista. Se incluye también «un conjunto de trabajos de investigación de temática comparatista junto a conferencias que se dictaron en el Curso de Verano de la UNED del año 2000 en Pontevedra sobre Castelao y su tiempo, y de charlas referentes a los Encuentros de Narrativa castellana, 
catalana, galega y vasca, que se celebraron a lo largo del curso 2000-2001 en Donostia, Barcelona, Málaga y A Coruña».

En el de 2003 (volumen VIII) aparece un artículo de nuestro profesor: $O$ galego e a escola lingüística española, de considerable extensión (pp. 157180). Y dado que define muy bien su línea de trabajo y de pensamiento, damos los epígrafes y la conclusión: $\mathrm{O}$ castelanismo racista de Menéndez Pidal; O tópico pidaliano da literatura castelá máis desenvolvida; $\mathrm{O}$ mito dos primeiros textos literarios; O castelán, lingua espontánea e tan propia de Galicia, Cataluña e Euskadi como as linguas autóctonas destas comunidades; O mito das linguas imperiais superiores e o castelán como lingua superior; A obsesión polo termo español fronte a castelán; A sistematización de Amado Alonso en Castellan, español, idioma nacional e a sua extraordinaria fortuna; Os exemplos dos gramáticos; A extensión do castelán nas comunidades non castelás; Un novo concepto de nacionalidade: a nacionalidade española ou castelá; A descalificación da oposición; Os resentidos continuadores rexionalistas do anónimo gramático de Lovaina; A oposición de Castelao. Y he aquí la Conclusión:

...a escola lingüística española e mesmo a intelectualidade castelá máis caracterizada —o propio Ortega - elaboran un discurso sobre o galego — tamén sobre as outras linguas de España non castelás - que para nada ten en conta a realidade sociolingüística nin cultural destas comunidades. $\mathrm{O}$ discurso, como tentaremos demostrar polo miúdo nun libro de próxima aparición, continúa hoxe en día. ${ }^{2}$

El volumen IX recoge otras actividades marcadas con el mismo sello como las I Converses Filològiques, efectuadas en el centro cultural de Blanquerna, de la Generalitat de Catalunya- y se dibuja como un monográfico ${ }^{3}$; pero en éste no consta la participación del profesor Rodríguez Alonso. Con las X Jornadas, desde 1999, se completa el ciclo de las ya tradicionales Jornadas, pero siguen las actividades habituales en congresos o seminarios, a menudo con extensiones a otras Universidades aparte de las madrileñas, como Santiago de Compostela, o a Centros Asociados de la UNED (Cervera y Segovia), y contando particularmente con el apoyo del centro cultural Blanquerna, recién citado, que acoge también la perspectiva multicultural, organizando presentaciones de libros, ciclos de lectura, etc. Continúa mientras tanto la colaboración de nuestro profesor, figurando en el consejo de redacción como profesor asociado de Lengua y Literatura gallegas, hasta el volumen XIII (2007-2008).

Para cerrar, me voy a remontar a la coyuntura que propició nuestro conocimiento, que fue la gestación del Diccionario de las lenguas de España (Anaya 1985). Esta obra, dirigida por Enrique Fontanillo — de quien aprendimos a la par una buena base lexicográfica - y prologada por el profesor Alonso Zamora

2 No hemos sabido localizar, dentro del espectro de manuales de lengua y de historia de la literatura de los que es autor, a qué libro se refiere aquí.

3 Se titula Del Humanismo; se hizo en homenaje a Miquel Batllori, fallecido en dicho año, y recoge artículos de los 19 volúmenes de su obra completa. 
Vicente, abrió por primera vez en lexicografía el panorama a la perspectiva comparatista hispánica. Lástima que no se hubiera inventado todavía el whatsapp ni los mails porque el resultado hubiera sido mucho más rico y efectivo. Hay que decir que nuestro trabajo nos llegaba de uno a otro redactor por medio de un motorista que - de vez en cuando, esporádicamente - nos entregaba las propuestas de las otras lenguas a efectos de poder dar en las notas de los vocablos comparaciones o comentarios lingüísticos; pero es obvio que esta vía, sin una labor en conjunto, apenas permitía el intercambio y la comunicación, y menos aún las rectificaciones.

Manolo, amigo, los que contamos aún con unos días más que tú, te recordamos con afecto.

\section{BIBLIOGRAFÍA}

Butinyà, J. (2003) «Sobre les jornades de llengua i literatura catalana, gallega i basca», Estudis Romànics 25, pp. 475-477. 